\title{
PENERAPAN PSIKOLOGI DESAIN PADA ELEMEN DESAIN INTERIOR
}

\author{
Budi Setiawan; Ulli Aulia Ruki \\ Interior Design Department, School of Design, BINUS University \\ Jln. K.H. Syahdan No.9, Palmerah, Jakarta Barat 11480 \\ bsetiawan@binus.edu; ulliaulia@gmail.com
}

\begin{abstract}
One of main interior designer's assignments is to solve the problem within the facility. Problems may occur because the activities of design decision had done or will be done on the facility are not maximized. This problem can be reduced by rethinking the design through psychology design. Utilizing psychology design will help designer decide a better judgment of objects that affects the person using it in routine. The example of interior objects is wall, door, floor, color, and other elements of interior. Desk research method was used to support this article trough data collection from books and other professional institution websites. At the end, the conclusion of this article does not directly impact the result since it took time to persuade judgment of the user, but positively it will construct designer to rethink the design object.
\end{abstract}

Keywords: the psychology of design, element of interior design

\begin{abstract}
ABSTRAK
Salah satu tugas utama sebagai desainer interior adalah melakukan pemecahan masalahan yang ada pada suatu fasilitas. Permasalahan yang muncul dapat dipicu oleh aktivitas yang sudah terjadi ataupun akan terjadi pada fasilitas tersebut jika ada keputusan desain yang kurang maksimal. Ilmu terapan psikologi desain digunakan karena pengguna dari suatu fasilitas adalah orang yang dapat secara langsung menilai apakah desain tersebut memberikan kepuasan ataupun tidak. Dalam hal ini, kepuasan yang dimaksud adalah perihal desain elemen yang ada pada desain interior seperti lantai, dinding, ceiling, dan juga elemen interior lainnya. Sebagai pendukung data yang ada, metodologi yang digunakan adalah menjabarkan data literatur (desk research) dari buku serta website institusi profesional. Simpulan tulisan ini adalah memperkenalkan psikologi desain terapan ini kepada desainer interior sehingga meminimalkan keputusan desain yang kurang baik.
\end{abstract}

Kata kunci: psikologi desain, elemen desain interior 


\section{PENDAHULUAN}

Suatu benda dapat terbuat karena melalui proses desain. Sementara, suatu desain melewati beberapa proses berpikir. Sebelum objek tersebut digunakan, ada pemikiran dasar yang biasanya digunakan oleh para desainer, yaitu 5W1H (who, what, where, when, why \& how). Setelah pemikiran yang mendasar tersebut, analisis digunakan untuk mengurangi beberapa kesalahan. Analisis tersebut yaitu dengan melakukan eksplorasi beserta trial and error dan dapat menemukan style yang lebih personal serta menemukan tempat yang dapat memenuhi perasaan seperti di rumah sendiri.

Suatu desain dapat mempunyai nilai lebih. Nilai tersebut mampu melebihi nilai estetika dan bukan sekadar dekorasi. Hal ini yang dinamakan dengan psikologi desain. Psikologi desain mencari sesuatu yang dapat memberikan penyatu ruang dengan benda. Lebih jauh lagi, psikologi desain dapat membangkitkan memori yang terpendam.

Psikologi desain tidak mungkin dipelajari dalam waktu singkat. Oleh karena itu, ditawarkan metode yang lebih singkat. Metode yang dimaksud adalah memperkenalkan metode pemikiran dari psikologi desain. Metode psikologi desain kurang lebihnya dapat diketahui dan dapat dipertimbangkan pada saat mendesain.

\section{METODE}

Penelitian menggunakan metode desk research. Metode desk research atau biasa disebut secondary research merupakan teknik penelitian yang berdiri sendiri dan merupakan awal penelitian dan pioneer untuk penelitiaan yang utamanya. Penelitian desk research mencari informasi dari beberapa penelitian yang sudah ada, seperti dari media, Internet, dan juga beberapa publikasi. Setelah itu, penelitian akan dicek-silang referensi dengan data yang lain. Gambar 1 adalah diagram metode penelitian dalam artikel ini. Diagram diambil berdasarkan Weinschenk (2011).

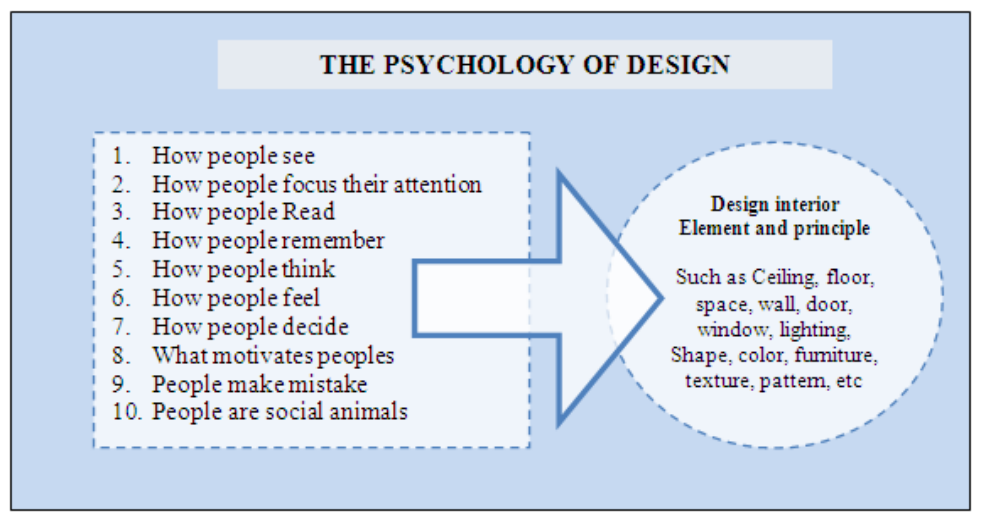

Gambar 1 Metode Penelitian

Berdasarkan Gambar 1 diketahui ada 10 hal yang harus diperhatikan desainer dalam menerapkan desain pada sebuah Interior. Desainer dapat memerhatikan cara orang melihat, membaca, merasakan, mengambil keputusan, dan perihal lainnya. Para desainer atau mahasiswa yang belajar desain interior diharapkan dapat meminimalkan kesalahan pada setiap keputusan desain dan memaksimalkan kepuasan yang dirasakan oleh pengguna interior tersebut. 


\section{HASIL DAN PEMBAHASAN}

\section{Bagaimana orang melihat (How people See)}

Weinschenk (2011:2) menyebutkan apa yang dilihat bukan selalu apa yang akan diterima oleh otak. Karena apa yang terlihat oleh mata atau optik manusia dapat disimpulkan berbeda. Dari Gambar 2 berikut ini terlihat bahwa garis A terlihat lebih panjang dari yang B. Pada kenyataannya garis A dan B memiliki panjang yang sama. Hal ini merupakan bukti dari suatu penampilan yang tertangkap oleh optik dapat memberikan persepsi yang berbeda. Gambar berikut adalah contoh dari sesuatu yang disebut optical illusions show us the errors.

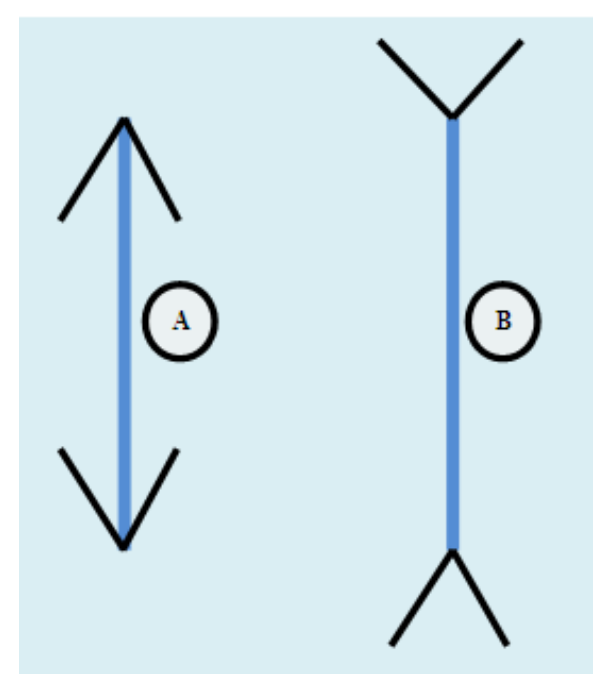

Gambar 2 Contoh dari Gambar yang dapat memberikan Ilusi

Dalam bidang interior, hal ini dapat berfungsi untuk memberikan kesan mengenai ruang (spatial) baik itu lebih tinggi/rendah atau lebih luas/sempit. Selain mengenai ruang, ada juga bidang yang bisa dibuat lebih menarik dengan warna, bentuk, pattern, texture, dan material

\section{Bagaimana Orang Memfokuskan Perhatian (How people focus their attention)}

Beberapa dari desain mempunyai maksud dan tujuan. Hal ini dapat terlihat pada sebuah desain kemasan. Terkadang mereka melebih-lebihkan suatu produk yang ada di kemasan tersebut. Produk tersebut diharapkan dapat menarik konsumen untuk dapat setidaknnya memerhatikan dan juga membelinnya.

Begitupun dengan desain suatu interior di sebuah public space. Sebagai contoh, interior toko pakaian harus dapat memberikan rasa ketertarikan calon pembeli dengan membuat suatu etalase atau jendela agar dapat memajang benda yang dijual. Dengan ilmu tambahan seperti tata pajang (visual merchandise), maka seorang desainer diharapkan mampu membuat ruangan terlihat tidak monoton atau membosankan.

Tujuan dari poin ini adalah menampilkan sesuatu desain dengan targetnya adalah menarik fokus dari calon pembeli untuk dapat masuk ke interior toko yang didesain. Agar lebih jelas, gambar dapat dilihat sebagai berikut. 


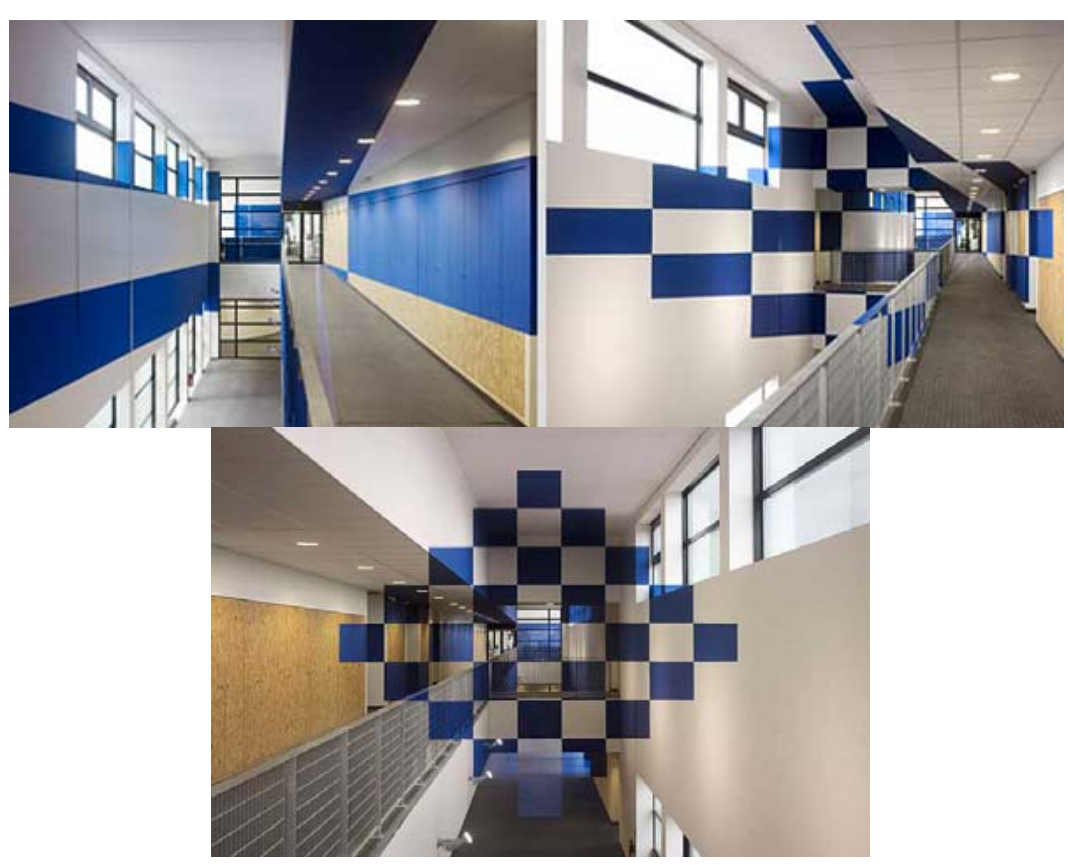

Gambar 3 Contoh dari Gambar yang Dapat Menarik Perhatian

Dari gambar interior tersebut, lorong yang tadinya membosankan dapat terlihat menarik. Hanya dengan menambahkan konsep grafis dan pewarnaan membuat area lorong tersebut bervolume serta menarik perhatian seseorang untuk mendekati area tersebut.

\section{Bagaimana Orang Membaca (How People Read)}

Sebagian dari orang lebih mudah memilih untuk membaca dengan tulisan yang lebih pendek, sedangkan menurut penelitian, seseorang membaca lebih cepat dengan paragraf yang panjang seperti contoh Gambar 4 berikut.

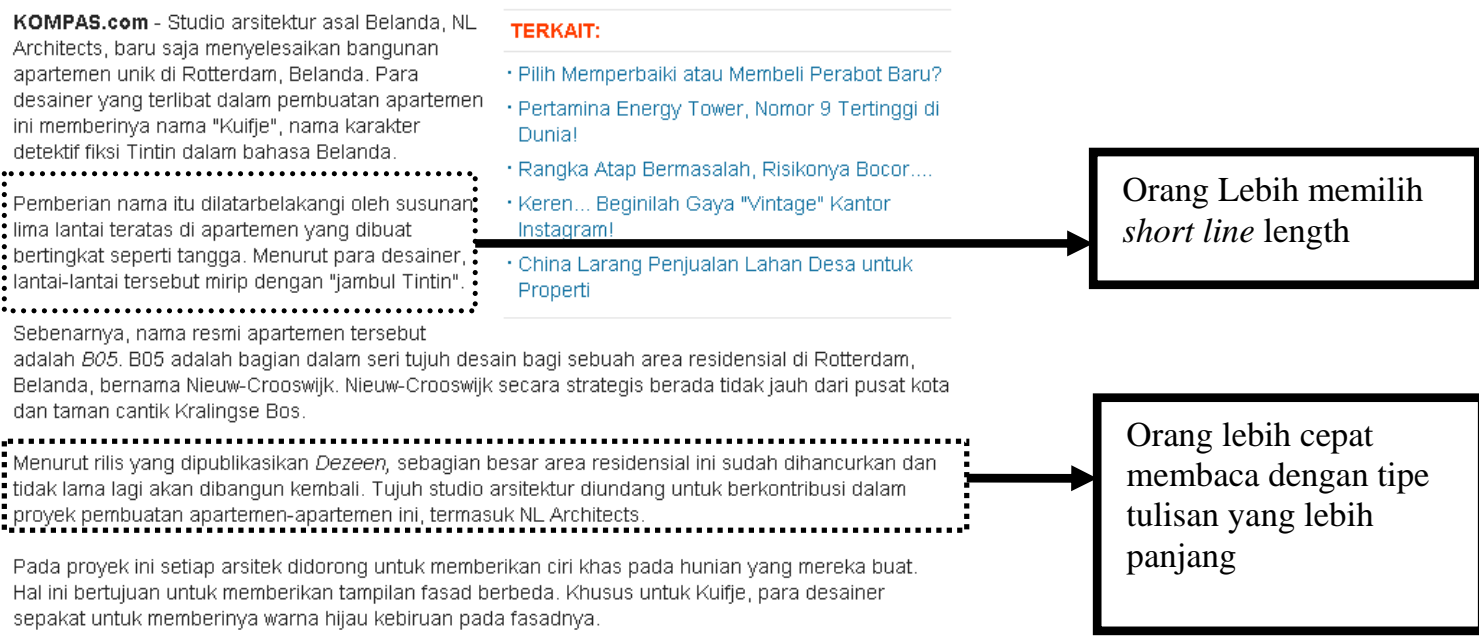

Gambar 4 Contoh dari bagaimana Orang Membaca

(Diela, 2013) 
Untuk pendekatan dari bidang interior, ada baiknnya desain signage juga diperhatikan. Hal ini akan berpengaruh terhadap informasi yang akan diberikan kepada klien yang masuk di interior tertentu. Terlebih pada fasilitas publik, signage dapat menjadi penting bila berkaitan dengan prosedur keselamatan haruslah mudah dibaca dan posisinya harus mudah dilihat.

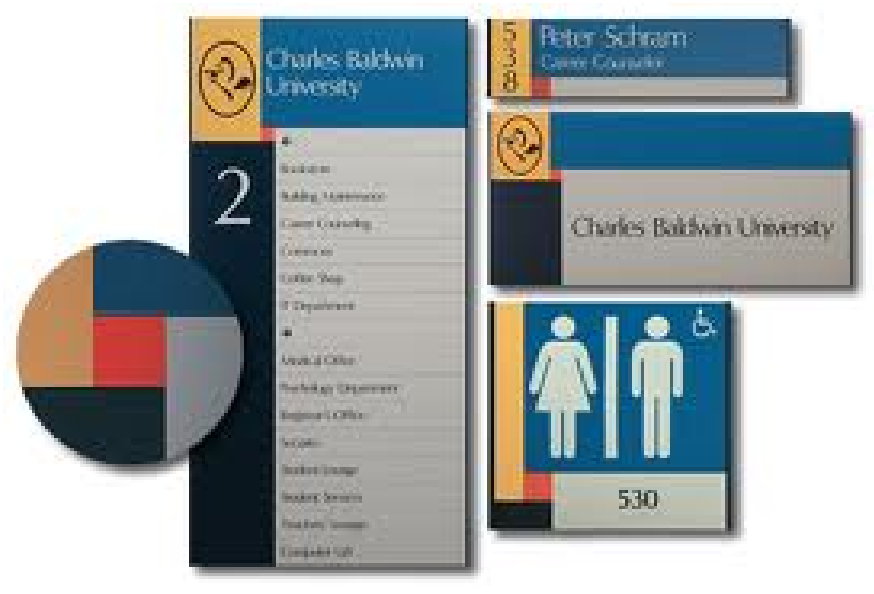

Gambar 5 Contoh Dari Signage

\section{Bagaimana Orang Mengingat (How People Remember)}

Sebagian dari orang terkadang dapat mengingat dengan logo, lambang ataupun sesuatu bentuk yang dapat secara cepat dibandingkan dengan kata-kata. Namun demikian, ada beberapa kata yang pasti seperti kursi, meja, pintu, jendela yang lebih mudah dingat secara jangka panjang, dibandingkan dengan kata-kata yang lebih abstrak seperti (keadilan, demokratis).
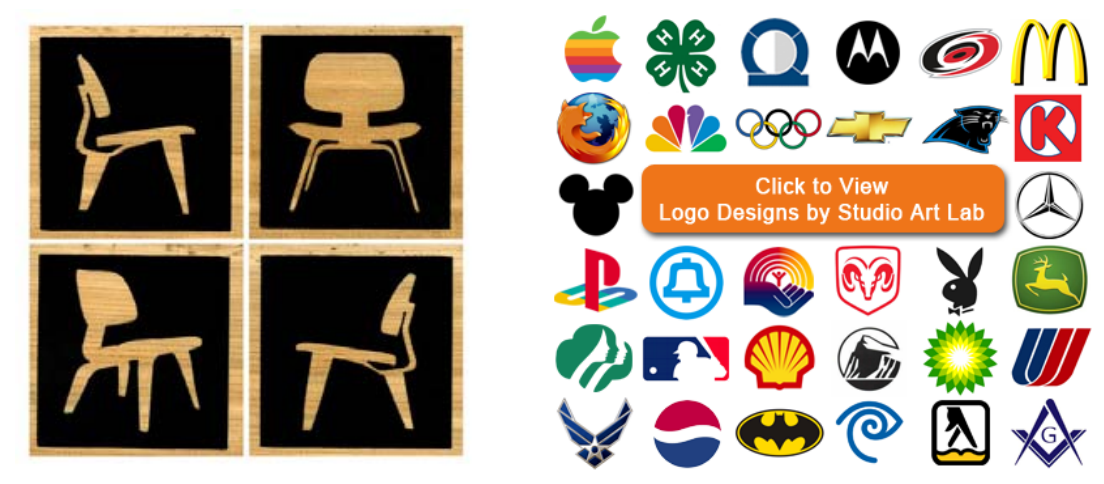

Gambar 6 Pengenalan Gambar logo untuk memudahkan orang untuk mengingat

Pengulangan (rhymes) selalu lebih mudah diingat. Selain itu terkadang beberapa dot dapat juga dipakai untuk membantu orang dalam mengingat. Ada kalanya suatu elemen desain seperti garis dan warna sangatlah membantu pembentukan image atau mem-branding suatu interior pada sebuah public space. 


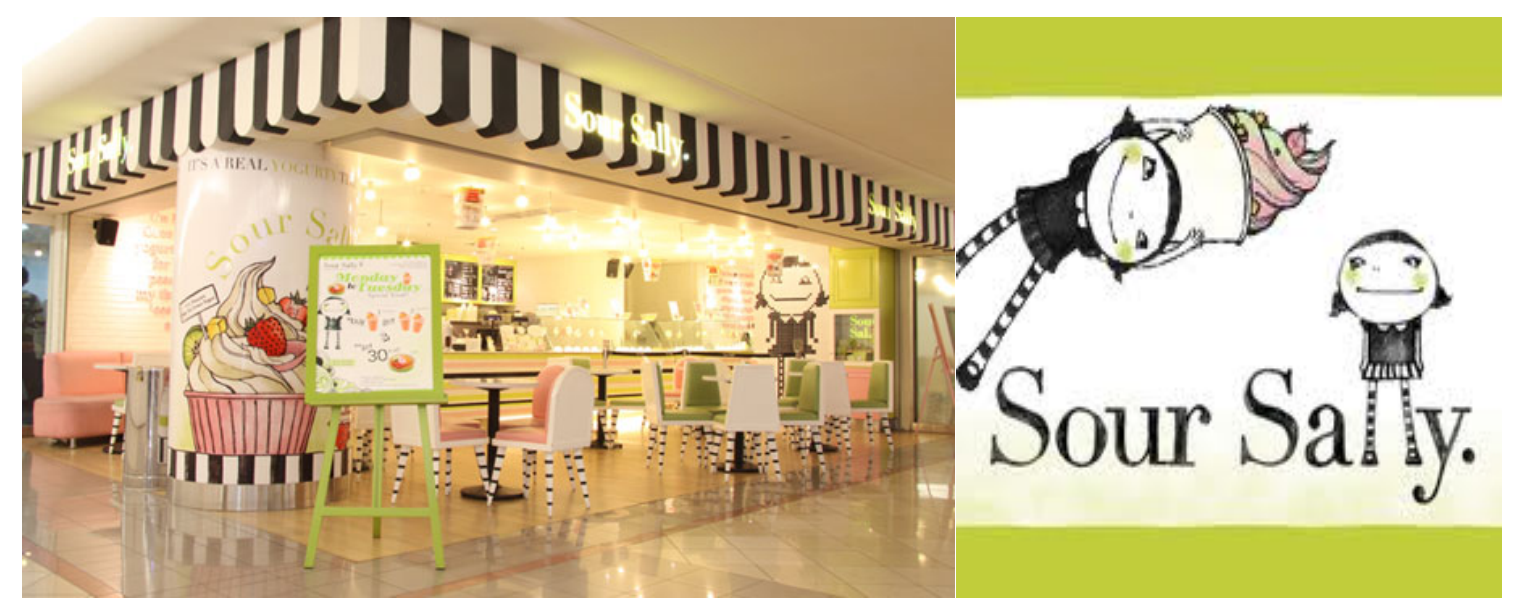

Gambar 7 Contoh Interior di public space yang mudah diingat

\section{Bagaimana Orang Berpikir (How People Think)}

Weinschenk (2011) menjelaskan beberapa poin penting untuk desainer dalam mengetahui cara orang berpikir. Hal ini akan membantu desainer dalam membaca pikiran klien dalam menentukan apa yang mereka inginkan. Pertama, orang lebih baik dalam belajar dengan contoh. Artinnya desainer sebaiknya menjelaskan konsep dengan sebuh contoh dan perumpamaan. Kedua, orang mudah menerima informasi dengan cara bercerita. Oleh karena itu, banyak desainer terkadang membuat story board ataupun mood board untuk mendelegasikan ide kepada beberapa orang yang berada dalam 1 tim desainnya. Ketiga, orang juga lebih menyukai sesuatu yang dikategorikan. Sebagai contoh, untuk sebuah interior biasannya dilakukan pembagian zona untuk memudahkan pembagian konsep ruang dan penghitungan kapasitas ruangnya.

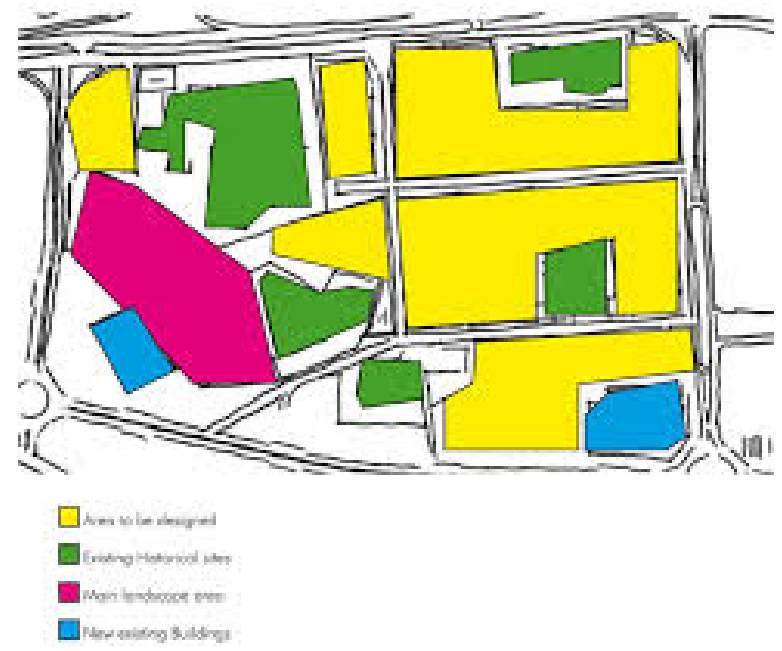

Gambar 6 Contoh dari Diagram Bubble yang menjelaskan Pembagian Zona pada sebuah Interior

Keempat, suatu kebudayaan juga dapat membuat seseorang berpikir dengan cara yang berbeda, karena dipengaruhi oleh latar belakang tempat sekeliling seseorang bertumbuh dewasa. 


\section{Bagaimana Orang Merasakan (How People Feel)}

Untuk kasus interior manusia mempunyai 5 pancaindra yang dapat digunakan. Seperti contoh adalah menggunakan wewangian kopi untuk sebuah kafe kopi ataupun juga dengan wewangian

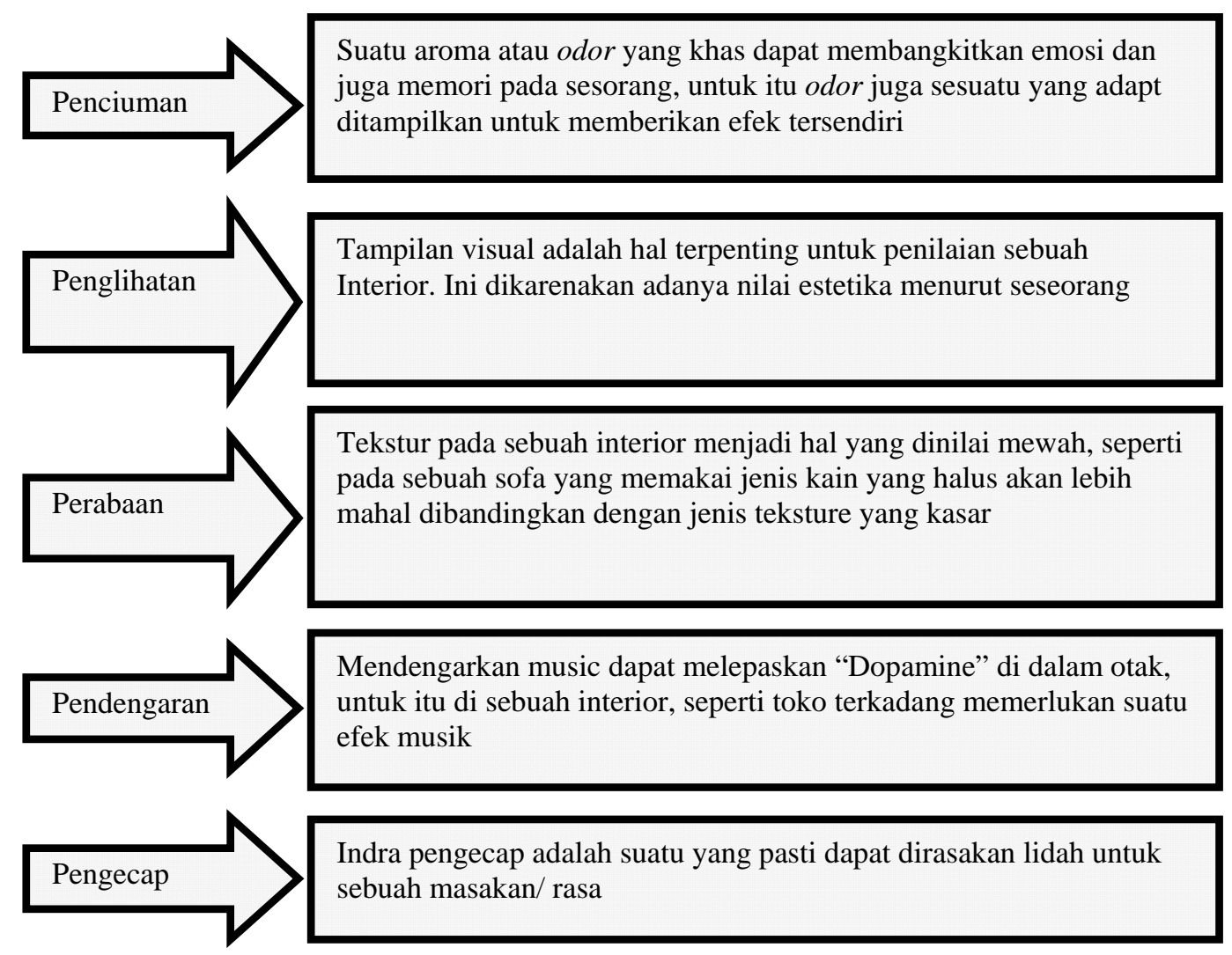

Gambar 7 Pancaindra yang Digunakan

\section{Bagaimana Orang Mengambil Keputusan (How People Decide)}

Menurut kebanyakan orang membuat keputusan secara tidak sadar. Contohnya saat seorang memikirkan akan membeli sebuat televisi untuk rumah. Dia melakukan beberapa research tentang TV apa yang akan dibeli dan cara termudah adalah melalui Internet. Faktor apa saja yang terlibat dalam proses pembuatan keputusan ini. Hal ini bukan seperti proses yang dibayangkan. Orang selalu berpikir bahwa mereka telah berhati-hati dan teliti dengan logika menimbang semua faktor relevan seelum mengambil keputusan. Pada kasus TV ini, orang akan mempertimbangkan ukuran TV yang paling cocok untuk ruang, merek yang paling sering dilihat dapat diandalkan, harga yang kompetitif, kapan waktu yang paling tepat untuk membeli, dan seterusnya. Orang sudah mempertimbangkan semua faktor tersebut dengan sadar, tetapi penelitian tentang pengambilan keputusan menunjukan bahwa sebenarnya keputusan yang diambil sepenuhnya secara tidak sadar.

Pengambilan keputusan secara tidak sadar termasuk faktor berikut. Pertama, apa yang orang lain putuskan untuk dibeli: "saya melihat TV dengan merk tertentu mendapat rating yang tinggi dan review yang bagus pada website atau majalah.” Kedua, komitmen personal yang konsisten: "saya adalah orang yang selalu memiliki sesuatu yang mutakhir, teknologi terbaru.” Ketiga, dengan memiliki benda tertentu, kita bisa membalas sesuatu atau membayar utang social (resiprok): "teman selalu 
mengundang saya kerumahnya untuk menonton pertandingan bola. Saya pikir sudah saatnya kita mengundang mereka ke tempat kita untuk menonton, jadi sebaiknya saya memiliki TV setidaktidaknya sebagus yang dia miliki.” Keempat, ketakutan akan kehilangan: "TV ini sedang diskon, dan jika saya tidak membelinya sekarang, harganya mungkin akan naik besok dan saya mungkin tidak dapat membelinya lagi.” Kelima, keinginan, motivasi dan kekuatiran-kekuatiran tertentu dalam diri kita.

Hampir semua proses mental dalam keadaan tidak sadar, begitu pula keputusan-keputusan yang dilakukan. Namun ketidaksadaran seperti contoh tidak berarti irasional atau salah. Seorang dihadapkan kepada sekian banyak data yang meluap dan tidak muat dalam otak (jutaan data yang masuk ke dalam otak setiap detiknya) dan kesadaran jiwa tidak akan dapat memproses semuanya. Ketidaksadaran ini yang kebanyakan terlibat dalam proses pengolahan data tersebut dan mengambil keputusan sesuai dengan guidelines dan aturan-aturan yang sesuai pada interest selama ini.

Untuk mendesain sesuatu yang membuat atau “mendesak" orang lain untuk mengambil tindakan tertentu, anda harus mengetahui motivasi atau dorongan-dorongan "ketidaksadaran" dari target market anda. Ketika seseorang mengungkapkan alasan mereka membuat sebuah keputusan, kita boleh saja berpikir skeptis tentang itu. Karena pengambilan keputusan bersifat tidak sadar, mereka mungkin tidak sadar alasan yang sebenarnya dari keputusan tersebut. Walaupun orang membuat keputusan berdasarkan factor ketidaksadaran, mereka menginginkan alasan rasional dan logis. Jadi anda tetap harus menyediakan alasan-alasan yang rasional itu.

\section{Apa yang Memotivasi Seseorang (What Motivates People)}

Pada dunia desain, banyak sekali hal yang harus diperhatikan. Salah satunya mengetahui motivasi dari target market dalam memilih sesuatu. Perlu dilakukan studi tentang hal ini. Ketika seorang desainer meng-interview orang tentang bagaimana orang akan menggunakan hasil karyanya, berhati-hatilah saat menginterpretasikan atau menganalisa hasilnya. Anda akan memiliki tendensi untuk berpikir tentang apa yang akan orang lakukan, berdasarkan personal seseorang dan melewatkan factor situasional. Cobalah untuk melakukan cross-check pada diri sendiri. Jika pekerjaan anda membutuhkan banyak pertimbangan tentang mengapa orang melakukan apa yang mereka lakukan, anda mungkin perlu berhenti sebelum mendapatkan kesimpulan yang didapat dan bertanya, "apakah saya mengambil kesimpulan berdasarkan penjelasan personal?”

Saat merancang interior, kita benar-benar harus mengetahui apa yang diinginkan oleh klien. Tidak hanya bagus atau cocok menurut seorang desainer, tetapi yang paling penting adalah apa yang benar-benar dibutuhkan saat menggunakan hasil rancangan disainer. Kemudian dari hal mendasar tersebut baru dapat kita sempurnakan dengan elemen estetis. Form follow function, kemudian aesthetic follow function.

\section{Orang Dapat Melakukan Kesalahan (People Make Mistake)}

Dalam dunia desain, produk atau karya yang dihasilkan oleh disainer dan digunakan oleh customer, pasti akan terjadi kesalahan dalam penggunaan atau pemakaiannya. Untuk itu diperlukan tes pemakaian, pendataan, kemudian perbaikan-perbaikan apa yang harus dilakukan untuk menanggulanginya, terutama pada hasil-hasil negatif. Perlu menjadi penekanan, tidak semua kesalahan adalah sesuatu yang jelek. Dimitri van der linden (2001) melakukan penelitian bahwa suatu error dapat berujung kepada hal positive atau hasil yang netral. 


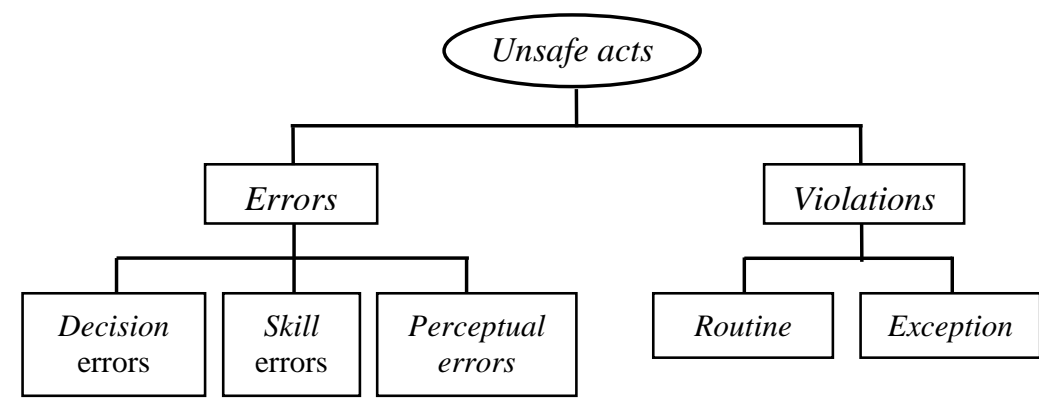

Gambar 7 Contoh type error HFACS

(Human Factors Analysis and Classification System)

Menurut penelitian, 2 orang psychologist Robert Yerkes dan John Dodson (New World Encyclopedia, 2013), orang dapat melakukan kesalahan lebih banyak jika dilakukan dalam suatu tekanan. Untuk itu terkadang desainer atau orang yang memerlukan tingkatan kreativitas yang tinggi, mereka memerlukan lingkungan yang tidak dalam tekanan.

\section{Orang (people are social animals)}

Kadangkala manusia menganggap kehidupan social tidak terlalu penting. Manusia akan menggunakan apa saja di sekitar mereka untuk menjadi sosial, dan itu termasuk ruang, tempat tinggal, dan benda pribadi untuk menunjukkan identitas masing-masing. Aristoteles mengatakan: "Man is by nature a social animal; an individual who is unsocial naturally and not accidentally is either beneath our notice or more than human. Society is something that precedes the individual. Anyone who either cannot lead the common life or is so self-sufficient as not to need to, and therefore does not partake of society, is either a beast or a god."

Untuk bidang interior, pola ini sudah dipakai yaitu dengan mengkategorikan ruangan menjadi area zona yang berbeda yaitu zona private, zona semi-private, zona semi-public, zona public, dan zona service. Selain zona public itu perlu dibuat sebuah area berkumpul yang dapat digunakan untuk berinteraksi. Sehingga kebutuhan manusia akan hidup sosial dapat terpenuhi. Untuk menunjang proses interaksi tersebut, agar tidak sekedar menjadi zona public biasa, diperlukan sarana penunjang seperti tempat duduk, dan lain sebagainya. Dengan demikian secara psikologis, manusia akan dapat berinteraksi dengan alami.

\section{SIMPULAN}

Psikologi desain memegang peranan penting dalam sebuah perancangan. Hasil akhir yang ingin dicapai oleh desainer harus matang dalam berbagai faktor. Setelah $5 \mathrm{~W}+1 \mathrm{H}$ diterapkan dalam konsep perancangan, kesepuluh poin psikologi desain akan semakin mempertajam pemikiran desainer. Psikologi desain yang dibahas dalam artikel ini berdasarkan Weinschenk (2011).

Psikologi desain tidak hanya sebatas pemilihan warna, bentuk, tekstur, permainan garis, sampai tata letak desain interior rumah juga bisa memengaruhi psikologi penghuni rumah. Baik itu masalah ketenangan, emosi dan kesejukan ruangan. Unsur ruang yang memengaruhi sisi psikologi interior desain juga termasuk didalamnya; penglihatan, perasa, pendengaran, dan penciuman. Dalam proses merancang tidak hanya cara berpikir kita yang perlu kita ketahui dengan jelas, tetapi juga cara berpikir klien dan orang pada umumnya. Bagaimana desainer dan klien melihat sesuatu, focus pada sebuah konsep, mengingat dan berpikir serta mengambil keputusan. Bagaimana desainer mengetahui 
motivasi dalam dirinya dan klien. Mengantisipasi kesalahan-kesalahan atas penggunaan hasil rancangannya, meminimalisir dan memperbaiki karyanya.

Psikologi desain interior adalah bagian dalam bidang psikologi lingkungan, yang menyangkut kondisi lingkungan interior. Ini adalah studi langsung dari hubungan antara lingkungan dan bagaimana lingkungan yang mempengaruhi perilaku penghuninya, dengan tujuan memaksimalkan pengaruh positif dalam hubungan ini. Melalui psikologi desain interior, kinerja dan efisiensi ruang serta kesejahteraan penggunanya dapat dikembangkan menjadi lebih baik.

\section{DAFTAR PUSTAKA}

Desk Research on Methodologies, Diakses 20 November 2013 dari http://www.research pmr.com/desk-research

Diela, T. (2013, 9 Desember). Apartemen Cantik Bergaya "Jambul Tintin". Diakses dari http://properti.kompas.com/index.php/read/2013/12/09/1624328/Apartemen.Cantik. Bergaya.Jambul.Tintin.

Linden, D. van der (2001). The nature and consequences of exploration strategies during complex tasks. In D. Harris (Ed.), Engineering psychology and Cognitive Ergonomics: Volume Six (pp. 299-305). London: Academic press.

Linden, D. van der, Sonnentag, S., Frese, M. \& Dyck, C. van (2001). Exploration strategies, performance, and error consequences when learning a complex computer task. Behaviour \& Information Technology, 20, 189-198.

New World Encyclopdia. (2013, 30 Juli). Robert Yerkes. Diakses dari http://www.newworldencyclopedia.org/entry/Robert_Yerkes

Tartakovsky, M. (2011). Design Psychology: Beyond Pretty Properties and Nice Knickknacks. Psych Central. Diakses 20 November, 2013, from

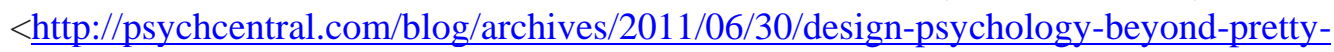
properties-and-nice-knickknacks/>

Weinschenk, S. (2011). 100 Things every Designer Needs To Know About People. New Riders. 